\title{
Introduction: Towards a more open and dynamic approach on cluster policy Robert Hassink and Dirk Fornahl
}

\section{BACKGROUND}

Cluster policies have been popular in many industrialized countries for a long time (OECD 2007; Borrás and Tsagdis 2008; Njøs and Jakobsen 2016). They can be regarded as part of a broader set of regional innovation polices that have developed strongly since the mid-1980s. This surge is mainly due to the increasing importance of the regional level with regard to diffusion-oriented innovation support policies (Fritsch and Stephan 2005; Asheim et al. 2003; Nauwelaers and Wintjes 2003; Prange 2008; OECD 2010, 2011). Partly funded by national and supranational support programs and encouraged by strong institutional set-ups found in successful regional economies such as Baden-Württemberg in Germany and Emilia-Romagna in Italy, many regions in Europe have been setting up science parks, technopoles, technological funding schemes, innovation support agencies, community colleges, cluster policies and initiatives to support the smart specialization of industries (Enright 2003; Foray 2015). The central aim of these regional innovation policies is to support regional endogenous potential by encouraging the diffusion of new technologies both from universities and public research establishments to small and medium-sized enterprises (SMEs), between SMEs and large enterprises (vertical cooperation) and between SMEs themselves (horizontal cooperation). Cluster policies are just one part of these broader regional innovation policies and often we find several cluster initiatives under the roof of one regional innovation policy.

However, complaints have become louder about too standardized cluster and regional innovation policies, due to benchmarking and learning from best-practice initiatives (Tödtling and Trippl 2005). These complaints can be seen in a broader scholarly discussion in favour of a place-based approach towards regional development policy (Barca et al. 2012; OECD 2011; Ebbekink and Lagendijk 2013). One way to solve this one-size-fitsall problem is emphasizing specific barriers in regional innovation systems 
(Tödtling and Trippl 2005). Another promising approach is to focus cluster policies on the specific needs of firms depending on the stage of development (emergence, growth, sustainment or decline) their cluster is in. In this edited book, these stage-specific cluster policies are analyzed and evaluated. Moreover, several chapters also focus on smart specialization policies to promote regional development by taking into account the emergence and adaptation of clusters and industries.

So what exactly are cluster life cycles and how are they related to cluster policies? Although clusters are regarded as important elements in economic development (Asheim et al. 2006), the strong focus on the way clusters function is contrasted with a disregard for their evolutionary development: how clusters actually become clusters, how and why they decline, and how they shift into new fields and transform over time (Lorenzen 2005). As a reaction to this gap, and inspired by recent developments in evolutionary economic geography (Boschma and Frenken 2006), new life cycle approaches emerged (Boschma and Fornahl 2011; Menzel and Fornahl 2010). From 2011 until 2014, an international collaborative research project, named "Cluster Life Cycles: The Role of Actors, Networks and Institutions in Emerging, Growing, Declining and Renewing Clusters", sponsored by the European Science Foundation (10-ECRP-007), has also strived to fill the above-mentioned gap (see also Fornahl et al. 2015). This strand of literature connects the quantitative development of clusters with underlying qualitative changes and transformations. In doing so, it elaborates which dynamics, prerequisites and qualities are connected to the emergence, growth and decline of clusters in order to find patterns of cluster evolution. The literature mostly distinguishes between the emergence, growth or expansion, decline or transformation of the cluster (Enright 2003). It has elaborated three different elements that drive the cluster through different stages of their developments: actors, networks and institutions (Menzel and Fornahl 2010). Cluster dynamics are derived from the interdependencies of these different elements. Cluster dynamics are also based on context-dependent actions, whereby the context is usually described by institutions or networks. Moreover, cluster dynamics do not only depend on internal dynamics, external relations are also an integral part of cluster dynamics (Fornahl et al. 2015).

\section{AIMS}

This edited book therefore aims at analyzing and evaluating stage-specific cluster policies, with contributions both from academic researchers and consultants in the field. The topics dealt with include: 
- A better understanding of the specific initial conditions to justify policy interventions. The reasons for policy interventions are likely to change over the course of a cluster life cycle and hence the policy instruments used should change as well and should be targeted to the specific cluster needs.

- A core feature of a sustainable cluster is its ability to renew itself and to generate new developmental paths. This prevents clusters from decline and can even generate new growth impulses. The question is how cluster policies facilitate these processes. In this context, policies to induce strategies of smart specialization in regions and clusters are one policy instrument used in recent years.

- Clusters are not closed entities, but are embedded in an ecosystem of actors, linkages, rules, etc. This embeddedness - but especially the variety of these elements - seems to affect the developmental opportunities of clusters and will be one topic addressed in this volume.

- The management of cluster initiatives, learning processes among policymakers and managers of cluster initiatives and the employed strategies along the cluster life cycle are other topics dealt with in this volume.

This edited book contributes to a newly emerging literature on how the cluster life cycle concept can inform policies that are better adapted to the stage of the cluster and how these policies differ from static approaches that ignore the life cycle of clusters (Brenner and Schlump 2011; Ingstrup and Damgaard 2013). In contrast to static approaches, cluster policies that intend to sustain long-term viability of clusters would focus on supporting the adaptability and changes of a cluster. This not only requires knowledge about the functioning of clusters, but also about the patterns that are connected with their emergence, growth, decline and transformation. Future research would further disentangle the mechanisms and ways of how state actions affect clusters, from regulatory frameworks via supporting institutions to direct involvement (Fornahl et al. 2015). Understanding the dynamics that are connected to the emergence, growth, decline and transformation of clusters allows us to derive targeted policies to govern clusters during different phases of their development (Brenner and Schlump 2011). Therefore, this perspective analyzes the leverages that can be used to contribute to the emergence and growth of clusters as well as to prevent their decline. It also contributes to fine-tuning cluster policies, in particular, and to establishing modern, tailor-made, place-based regional innovation policy, in general. 


\section{STRUCTURE OF THE BOOK}

Four chapters in this book stem from researchers who have been involved in the European Science Foundation project: 10-ECRP-007 "Cluster Life Cycles: The Role of Actors, Networks and Institutions in Emerging, Growing, Declining and Renewing Clusters" (Grillitsch and Asheim, Chapter 4; Asheim et al., Chapter 1; Auer and Tödtling, Chapter 10; Mahroum and Al-Saleh, Chapter 14). Most of the chapters published in this book were presented at an international dissemination workshop that took place in Berlin on 23-24 June 2014, which was also sponsored by the European Science Foundation. In addition to the above-mentioned research project members, the other chapters were written by external academic researchers.

The book consists of 14 chapters in total, divided into three parts. Part I, consisting of seven chapters, deals with ideas how cluster policy should be designed. Over recent years, cluster policy has gained increased importance for improving the competitiveness of local industries and facilitating industrial transformation processes. Despite the popularity of the concept and its widespread use, surprisingly little is understood regarding the nature of these interventions and their impact.

In Chapter 1, Asheim, Isaksen, Martin and Trippl direct their attention to the role of clusters and public policy in new regional economic path development. New path development is analyzed from an institutional perspective by focusing on changes in the wider regional innovation system. They argue that new regional economic path development requires a broad-based policy approach. The case study focuses on two new regional economic growth paths in Sweden and Norway, namely the new media cluster in southern Sweden and the Oslo Cancer Cluster. The empirical analysis underlines the role that public policy can play in facilitating new regional economic path development.

Uyarra and Ramlogan (Chapter 2) explore the nature and the impact of policies that have been implemented with the goal of fostering clusters. By reviewing the evolving rationales underpinning cluster policy and the challenges associated with their implementations and evaluation, the chapter concludes with some general lessons and implications.

In Chapter 3, Vicente looks for more robust micro foundations of network structuring in clusters, disentangling how market and network failure arguments play together in cluster policy design. The aim is to show that, in spite of growing skepticism, new opportunities for cluster policy exist.

Grillitsch and Asheim (Chapter 4) elaborate how the integration of institutional variety can stimulate the combination of different types of knowledge, learning and modes of innovation, thereby promoting cluster 
renewal. The conceptual argument is illustrated with a case study of the maritime cluster in Møre og Romsdal, Norway, which is one of the globally leading clusters in this industry.

In Chapter 5, Fromhold-Eisebith investigates learning effects between cluster initiatives in the same region, yet across different industrial sector groups. The author proposes that a "clusterscape" composed of various cluster initiatives that target different economic sectors in the same region provide the breeding ground for specific dynamics and advantages of collaborative learning. The chapter suggests a conceptual categorization of learning options between local cluster initiatives catering to different industry topics. Empirical underpinnings are provided, relating to the regional cases of Upper Austria (Austria) and Aachen (Germany), which juxtaposes a centralized institutional approach of intersectoral cluster support and the decentralized setting of an "ecosystem" of independently interacting cluster initiatives. Finally, potential influences of regional learning between cluster initiatives on cluster (policy) cycle dynamics are discussed.

Fosse and Normann address the relationship between the evolutionary process of cluster development and the strategies used by cluster project managers in Chapter 6. The determinants of the relationship between a cluster project's life-cycle stage and the network steering strategies applied are examined. They shed light on the question of what characterizes the relationship between a cluster project's life cycle and the network steering strategies applied.

Meier zu Köcker and Lämmer-Gamp (Chapter 7) attempt to set up core design features of future cluster policies in order to better cope with upcoming challenges. They also look at the implications for regions pondering how to design and implement their smart specialization strategies for regional economic growth.

Part II, consisting of two chapters, deals with the concept of smart specialization and the question of what cluster policy can learn from it. Smart specialization is a process addressing the missing or weak relations between R\&D and innovation resources and activities, on the one hand, and the sectoral structure of the economy, on the other (Foray 2015). The underlying rationale behind the smart specialization concept is that by concentrating knowledge resources and linking them to a limited number of priority economic activities, countries and regions can become-and remain - competitive in the global economy. This type of specialization allows regions to take advantage of scale, scope and spillovers in knowledge production and use, which are important drivers of productivity (Foray 2015). Cluster policy is also strongly related to the recent boom in policies related to smart specialization. According to Foray et al., smart specialization is "largely about the policy process to select and prioritize 
fields or areas where a cluster of activities should be developed, and to let entrepreneurs discover the right domains of future specialisation" (2011: 7, emphasis added). Although clusters are important building blocks of smart specialization strategies (OECD 2013: 50), these strategies sometimes can even be regarded as recycled cluster strategies (Foray 2015: 82; Morgan 2013; Valdaliso et al. 2014).

Benner deals in Chapter 8 with the question of how regional specialization develops and what role regional agents play in this process. The chapter draws on ideas of continuous analysis of cluster emergence, revolving cluster policy and smart experimentation, and proposes policyoriented methods for achieving regional specializations based on a combination of regional openness to new trajectories and the targeted promotion of new specializations. These ideas can serve as guidelines for evolutionary regional policies that acknowledge micro-level evolutionary dynamics and promote new path development.

In Chapter 9, Koschatzky, Kroll, Schnabl and Stahlecker analyze coexistence, competition and interdependence of cluster policy and smart specialization policies in Germany. They present evidence from four German states (Länder) that, despite a common national policy framework and a common set of institutions affecting the regional innovation systems, variations in cluster policy and the implementation of smart specialization strategies are possible. The integration of cluster policy in a smart specialization strategy is by no means automatic and easy. A proactive regional government, stakeholder involvement, a serious strategy process and a systemic approach are necessary.

Part III, consisting of five chapters, deals with different case studies of cluster life cycle policy. The chapters analyze the origin and development patterns of cluster initiatives, the transformation of regional economic structures and discuss the cluster life cycle frameworks in different regions and sectors.

In Chapter 10, Auer and Tödtling argue that the role of cluster policies differs between sectors and regions depending on particular framework conditions and development factors that might also change over time. On the firm level, the role of cluster policies seems to be even more diverse since particular firm needs and problems vary according to the companies' main activities, age and size. The authors investigate the environmental technology cluster in Upper Austria and the new media cluster in Vienna from this perspective. Both clusters differ with regard to the role of cluster policies.

Rothgang and Lageman (Chapter 11) explore the origin and development patterns of cluster initiatives which are analyzed by looking at Germany's Spitzenclusters, the initiatives funded by the federal program Spitzencluster-Wettbewerb (Leading-Edge Clusters Competition). Starting 
from a life cycle model of cluster initiatives that distinguishes five development stages, they found that the Spitzencluster initiatives essentially followed rather similar cyclical development paths.

Rehfeld and Nordhause-Janz analyze the transformation of regional economic structures in the Ruhr Area, an old industrial area, in Chapter 12. They discuss these transformation processes in the context of global (macro), regional, sectoral (meso) and actor-orientated constellations and dynamics. They argue that, in the case of the Ruhr Area, processes of decoupling and fragmentation have been inevitable stages in the reorientation and reformation of regional clusters over time. At the same time, regional and sectoral differences of sub-regions have led to greater variations in the overall economic structure of the Ruhr Area.

In Chapter 13, Cooke investigates the bankruptcy in 2012 of the leading cluster-building consultancy firm Monitor, founded by academic business guru Michael Porter. He draws his attention to flawed policy practices relying on the "discourse" approach to cluster-building. Attention is then refocused away from the "discursive" approach towards the material one, and an analysis is provided of processes of cluster evolution following divergent pathways in search of "platform" variety.

In the final chapter of this volume, Mahroum and Al-Saleh introduce the case of Abu Dhabi as an experiment in cluster development and provide early examination of the experience to date in light of the cluster life-cycle framework. The presented model of "cluster development" strategy is pioneered by the emirate of Abu Dhabi.

\section{OUTLOOK}

During the workshop as well as in the publications of this edited volume some upcoming topics could be identified, such as the identification of new clusters in time by early looking at sub-networks, intensive and scientific monitoring of firm performance in relation to the cluster support they have received, the increasing focus on societal needs in relation to cluster support and the emergence of new clusters.

In the following we want to focus on some other topics that are most relevant with regard to future cluster-oriented policies in our view. Up to now, policy instruments mainly focused on the establishment and support of cluster management and the services they provide as well as on the formation of linkages between cluster organizations - primarily those linkages related to $\mathrm{R} \& \mathrm{D}$ activities. These were in some cases complemented by new infrastructure, measures related to human capital or the support of entrepreneurship. This support was allocated to selected firms, research 
institutes, universities, cluster managements or consortia applying for funding. Although such policy was in many cases successful and provided a basis for promising developments, the contributions in this edited volume indicate some additional aspects that should be taken into account in future cluster policy.

First, most cluster support programs still focus on specific sectors, industries or technologies that are of high importance for regional development. At least the members of the applying consortium and local policymakers perceive this importance. But in the long run, such a focus might lead to negative developments resulting from lock-ins. A shift of focus might be more promising. This shift leads away from sectors or specific technologies and concentrates on important processes relevant for one or several sectors or technologies. Policymakers should focus more on these processes and dynamics and less on the existence of peculiar, important industries or technologies in a region. In the end, even the same organizations might be supported but not because they exist in a region and are important measured by the current numbers of employees, but because of the activities they conduct and the future importance of these activities for the region or the impulses they generate with regard to the accumulation of knowledge.

Second, and related to the first point, the core process is the renewal or reinvention of the cluster, which is relevant in the long run for both the cluster and the region. Hence, policy support should focus on the adaptability and changes of a cluster, the integration of new knowledge, the fusion of sectors or technologies, the emergence of new industries or technologies, and the use and generation of variety. Several chapters in this volume focus on smart specialization policies to promote regional development by taking into account the emergence and adaptation of clusters and industries. If smart specialization is really implemented and executed in this way, it might serve as a blueprint for future regional innovation and cluster policies. Currently there is still a lot of confusion as many buzzwords are created to draw academic and policy attention.

Third, until now only few programs (such as the Norwegian cluster policy program) take cluster development, cluster stages and transitions into account. Cluster policies should focus on specific problems that must be solved in a particular cluster stage and aim at the specific needs of firms depending on the stage of cluster development. This would imply much more targeted instruments. One example is presented by Vicente in Chapter 3 of this volume: policy support should not just provide funding for all network relations that are formed or suggested by the cluster organization. General network support measures might lead to rigid network structures with the same organizations receiving funding round after round for years because they are very successful in writing applications and probably even 
successful in executing a joint research project. On the negative side, the question is whether these organizations really still learn from each other. Maybe new actors in the region and the periphery of the network are not considered as partners although they can come up with new ideas. Thus, at some stages, policy support should lead to an opening of existing network structures with the opportunity of newcomers to join, while at other stages the coherence of the network has to be strengthened in order to generate synergies and increase productivity. The same consideration holds for policy support with regard to start-ups or the formation of human capital.

Fourth, in order to achieve this, the embeddedness of the cluster should be taken seriously. The cluster organizations and the cluster as a whole are embedded in a regional ecosystem consisting of other clusters, sectors or technologies and at the same time they are embedded in extra-regional innovation systems. This reality is often neglected by focusing support on specific clusters - meant as technologies or sectors. New policy programs aiming at cross-innovation activities or the internationalization of clusters are geared towards the opening up of clusters but should be used in a more systematic way.

\section{ACKNOWLEDGMENTS}

We are indebted to the European Science Foundation for providing us with financial support (10-ECRP-007) to organize the dissemination workshop on which this book is based.

\section{REFERENCES}

Asheim B., A. Isaksen, C. Nauwelaers and F. Tödtling (eds.) (2003), Regional Innovation Policy for Small-Medium Enterprises, Cheltenham: Edward Elgar Publishing.

Asheim, B., P. Cooke and R. Martin (eds.) (2006), Clusters and Regional Development: Critical Reflections and Explorations, London: Routledge.

Barca, F., P. McCann and A. Rodríguez-Pose (2012), The case for regional development intervention: place-based versus place-neutral approaches, Journal of Regional Science 52, 134-152.

Borrás, S. and D. Tsagdis (2008), Cluster Policies in Europe: Firms, Institutions, and Governance, Cheltenham: Edward Elgar Publishing.

Boschma, R. and D. Fornahl (2011), Cluster evolution and a roadmap for future research, Regional Studies 45(10), 1295-1298.

Boschma, R. and K. Frenken (2006), Why is economic geography not an evolutionary science? Towards an evolutionary economic geography, Journal of Economic Geography 6(3), 273-302. 
Brenner, T. and C. Schlump (2011), Policy measures and their effects in the different phases of the cluster life cycle, Regional Studies 45(10), 1363-1386.

Ebbekink, M. and A. Lagendijk (2013), What's next in researching cluster policy: place-based governance for effective cluster policy, European Planning Studies 21(5), 735-753.

Enright, M. (2003), Regional clusters: what we know and what we should know, in J. Bröcker, D. Dohse and R. Soltwedel (eds.), Innovation Clusters and Interregional Competition, Berlin: Springer.

Foray, D. (2015), Smart Specialisation: Opportunities and Challenges for Regional Innovation Policy, Abingdon: Routledge/Regional Studies Association.

Foray D., P. David and B.H. Hall (2011), Smart specialization: from academic idea to political instrument, the surprising career of a concept and the difficulties involved in its implementation, MTEI Working Paper, École Polytechnique Fédérale de Lausanne.

Fornahl, D., R. Hassink and M.P. Menzel (2015), Broadening our knowledge on cluster evolution, European Planning Studies 23, 1921-1931.

Fritsch, M. and A. Stephan (2005), Regionalization of innovation policyintroduction to the special issue, Research Policy 34, 1123-1127.

Ingstrup, M.B. and T. Damgaard (2013), Cluster facilitation from a cluster life cycle perspective, European Planning Studies 21(4), 556-574.

Lorenzen, M. (2005), Why do clusters change? European Urban and Regional Studies 12(3), 203-208.

Menzel, M.-P. and D. Fornahl (2010), Cluster life cycles - dimensions and rationales of cluster evolution, Industrial and Corporate Change 19(1), 205-238.

Morgan, K. (2013), The regional state in the era of Smart Specialisation, Ekonomiaz 83, 103-126.

Nauwelaers C. and R. Wintjes (2003), Towards a new paradigm for innovation policy?, in B. Asheim, A. Isaksen, C. Nauwelaers and F. Tödtling (eds.), Regional Innovation Policy for Small-Medium Enterprises, Cheltenham: Edward Elgar Publishing, pp. 93-220.

Njøs, R. and S.E. Jakobsen (2016), Cluster policy and regional development: scale, scope and renewal, Regional Studies, Regional Science 3(1), 146-169.

OECD (2007), Competitive Regional Clusters: National Policy Approaches, Paris: Organisation for Economic Co-operation and Development.

OECD (2010) Regional Development Policies in OECD Countries, Paris: Organisation for Economic Co-operation and Development.

OECD (2011) Regions and Innovation Policy, OECD Reviews of Regional Innovation, Paris: Organisation for Economic Co-operation and Development.

OECD (2013) Innovation-Driven Growth in Regions: The Role of Smart Specialisation, Paris: Organisation for Economic Co-operation and Development.

Prange H. (2008), Explaining varieties of regional innovation policies in Europe, European Urban and Regional Studies 15, 39-52.

Tödtling F. and M. Trippl (2005), One size fits all? Towards a differentiated regional innovation policy, Research Policy 34(1), 1203-1219.

Valdaliso, J.M., E. Magro, M. Navarro, M.J. Aranguren and J.R. Wilson (2014), Path dependence in policies supporting smart specialisation strategies: Insights from the Basque case, European Journal of Innovation Management 17, 390-408. 